OPEN ACCESS

Edited by:

José Hernández-Rodríguez, Hospital Clinic of Barcelona, Spain

Reviewed by: Arsen Arakelyan, Institute of Molecular Biology (NAS RA), Armenia

Segundo Bujan-Rivas, Hospital Vall Hebron, Spain Gayane Manukyan, Institute of Molecular Biology (NAS RA), Armenia

*Correspondence: Seza Özen sezaozen@hacettepe.edu.tr

Specialty section: This article was submitted to Inflammation,

a section of the journal

Frontiers in Immunology

Received: 04 December 2016 Accepted: 21 February 2017

Published: 23 March 2017

Citation:

Özen S, Batu ED and Demir S (2017) Familial Mediterranean

Fever: Recent Developments

in Pathogenesis and New Recommendations for Management.

Front. Immunol. 8:253.

doi: 10.3389/fimmu.2017.00253

\section{Familial Mediterranean Fever: Recent Developments in Pathogenesis and New Recommendations for Management}

\author{
Seza Özen*, Ezgi Deniz Batu and Selcan Demir \\ Department of Pediatrics, Division of Rheumatology, Hacettepe University Faculty of Medicine, Ankara, Turkey
}

Familial Mediterranean fever (FMF) is the most common monogenic autoinflammatory disease (AID) affecting mainly the ethnic groups originating from Mediterranean basin. The disease is characterized by self-limited inflammatory attacks of fever and polyserositis along with elevated acute phase reactants. FMF is inherited autosomal recessively; however, a significant proportion of heterozygotes also express the phenotype. FMF is caused by mutations in the MEFV gene coding for pyrin, which is a component of inflammasome functioning in inflammatory response and production of interleukin-1 $\beta$ $(\mathrm{IL}-1 \beta)$. Recent studies have shown that pyrin recognizes bacterial modifications in Rho GTPases, which results in inflammasome activation and increase in IL-1 $\beta$. Pyrin does not directly recognize Rho modification but probably affected by Rho effector kinase, which is a downstream event in the actin cytoskeleton pathway. Recently, an international group of experts has published the recommendations for the management of FMF. Colchicine is the mainstay of FMF treatment, and its regular use prevents attacks and controls subclinical inflammation in the majority of patients. Furthermore, it decreases the longterm risk of amyloidosis. However, a minority of FMF patients fail to response or tolerate colchicine treatment. Anti-interleukin-1 drugs could be considered in these patients. One should keep in mind the possibility of non-compliance in colchicine-non-responders. Although FMF is a relatively well-described AID and almost 20 years has passed since the discovery of the MEFV gene, there are still a number of unsolved problems about it such as the exact mechanism of the disease, symptomatic heterozygotes and their treatment, and the optimal management of colchicine resistance.

Keywords: familial Mediterranean fever, MEFV, pyrin, colchicine, Rho GTPases

\section{INTRODUCTION}

Familial Mediterranean fever (FMF) is the most common monogenic autoinflammatory disease (AID) over the world. Its prevalence is very high among people from the eastern Mediterranean such as Jews, Turks, Armenians, and Arabs $(1,2)$. However, patients from different ethnicities (such as Japan) are being increasingly recognized $(3,4)$. Self-limited inflammatory attacks of fever and polyserositis along with high acute phase response are the typical phenotype expected in FMF (5). The most significant complication of FMF is amyloidosis, and it is responsible for long-term 
morbidity and mortality (6). Although it is known to be inherited autosomal recessively, a substantial number of heterozygotes are present expressing the phenotypic characteristics (7).

Since the definition of $M E F V$ gene mutations underlying FMF in 1997, around 310 sequence variants in $M E F V$ gene have been detected (8). MEFV gene, located on chromosome 16 encodes for pyrin protein $(9,10)$. Pyrin, exists mostly in neutrophils and macrophages, has a key role in apoptosis and inflammatory pathways $(9,11)$. Mutated pyrin causes an exaggerated inflammatory response by uncontrolled interleukin-1 (IL-1) secretion (11). Recent studies have supplied information about the importance of the role of pyrin as a pattern recognition receptor (PRR), as well (12).

Colchicine is the mainstay of FMF treatment, and its regular use prevents attacks and suppresses chronic subclinical inflammation (13-15). Anti-IL-1 drugs emerged as promising treatment options in patients who fail to response or tolerate colchicine. Compliance to this orally administered drug is a problem. In resistant cases, the clinicians should also keep in mind whether the patient is compliant to the therapy (16). Recently, a group of international experts has published the recommendations for the management of FMF to guide physicians taking care of these patients (17).

In this review, we will discuss the new findings in the pathogenesis of FMF and the new recommendations for management.

\section{GENETICS OF FMF}

In 1997, mutations in the $M E F V$ gene, composed of 10 exons and located on chromosome 16 (16p13.3), were found to be associated with $\operatorname{FMF}(9,10,18)$. The gene encodes a 781 amino acid protein termed pyrin or marenostrin $(9,10,18)$. Only a few mutations had been defined in selected families when the genetic association was first described $(10,19)$. Up to date, according to the INFEVERS database, more than $310 \mathrm{MEFV}$ sequence variants have been reported (http://fmf.igh.cnrs.fr/infevers/). However, all variants are not associated with a disease phenotype and are termed "variants of uncertain significance." With the description of new mutations, concerns emerged for the adequacy of checking only the common mutations. Booty et al. sequenced the $M E F V$ gene in FMF patients and showed that screening the most common mutations instead of sequencing the whole gene appears sufficient to diagnose FMF in presence of clinical symptoms (20). In 2012, a group of clinical and molecular experts reached a consensus to test for a total of $14 M E F V$ variants if possible (21). These include nine clearly pathogenic variants (M694V, M694I, M680I, V726A, R761H, A744S, I692del, E167D, and T267I) and five variants of unknown significance (E148Q, K695R, P369S, F479L, and I591T) (21).

In the Eastern Mediterranean, the distribution of $M E F V$ mutations is quite similar. M694V is the most common mutation in Turk (5), Armenian (22, 23), Arab (24), and Jewish populations (25); however, it is less common in Arabs (26). The second most common mutation is M680I in Turks (5); and V726A in Armenians (22, 23), Arabs (24), and Jews (25). M680I is the third most common mutation in Armenians (23). M694I is mostly seen in the Arabic population (24). On the other hand, in populations where FMF is a rare disease, the aforementioned mutations are less common, and other mutations are also seen. For example, in Japanese patients, E148Q is the most common variant followed by M694I and L110P (3). The clinical variability in FMF could be partly explained by genetic heterogeneity. For instance, most experts agreed that M694V was associated with a severe disease phenotype (8).

Recently, evidence-based recommendations have been developed for genetic diagnosis of FMF by the Single Hub and Access point for pediatric Rheumatology in Europe (SHARE) initiative (8). These recommendations are presented in Table 1. According to these, patients homozygous for M694V should be considered at higher risk of early disease onset and developing a severe phenotype (8). Furthermore, the patients carrying two mutated alleles in position 680-694 on exon 10 are also considered at risk of having a more severe disease (8).

Another area of debate is E148Q variant. E148Q, the most frequent sequence alteration in the $M E F V$ gene (27), is the result of the substitution of glutamine for glutamic acid at codon 148 in exon $2(28,29)$. E148Q is a common variant in the general population; however, the pathogenic role of E148Q is still uncertain (30).

In 2000, in a case-control study, Ben-Chetrit et al. found a similar frequency for E148Q mutation both in patients and healthy controls and in patients and their asymptomatic relatives (27). Tchernitchko et al. also demonstrated that E148Q allele frequency was comparable among patients and asymptomatic relatives and they concluded E148Q as a benign polymorphism (31). However, other studies $(32,33)$ showed that patients with homozygous E148Q variant might have an FMF-like phenotype

TABLE 1 | Recommendations for familial Mediterranean fever (FMF) genetic diagnosis [adapted from Ref. (8)].

\section{Recommendation}

Strength of evidence

1. FMF is a clinical diagnosis, which can be supported but not excluded by genetic testing

2. Consider patients homozygous for M694V at risk of developing, with very high probability, a severe phenotype

3. FMF patients carrying two of the common mutated alleles (homozygotes or compound heterozygotes), especially for M694V mutation or mutations at position 680-694 on exon 10, must be considered at risk of having a more severe disease

4. The $E 148 Q$ variant is common, of unknown pathogenic significance, and as the only MEFV variant does not support the diagnosis of FMF

5. Patients homozygous for M694V mutation are at risk of early onset disease

6. Individuals homozygous for M694V who are not reporting symptoms should be evaluated and followed closely in order to consider therapy

7. For individuals with two pathogenic mutations for FMF who do not report symptoms, if there are risk factors for AA amyloidosis (such as the country, family history, and persistently elevated inflammatory markers, particularly serum amyloid A protein), close follow-up should be started and treatment considered

8. Consultation with an autoinflammatory disease specialist may be helpful in order to aid in the indication and interpretation of the genetic testing and diagnosis 
requiring colchicine treatment. In a recent study, it has been suggested that the disease was less severe, the disease onset was later, and the ratio of patients responding completely to colchicine was higher in-at least a portion of-patients homozygous for E148Q when compared to the patients with exon 10 mutations (34).

Shinar et al. defined E148Q as a variant of unknown significance (21) and according to the SHARE recommendations, E148Q, as the only $M E F V$ variant, does not support the diagnosis of FMF (8).

Although FMF is considered as an autosomal recessive disease, it was recognized that a significant portion of the patients had only one mutation in the $M E F V$ gene $(25,35)$. Marek-Yagel et al. examined heterozygote FMF patients and performed haplotype studies in FMF families (36). They concluded that in some cases, the disease in heterozygotes could not be distinguished from that of homozygous patients, and FMF could be viewed as a dominant condition with low penetrance. Booty et al. searched for a second $M E F V$ mutation in heterozygote patients who had a clinical diagnosis of FMF (20). However, re-sequencing the entire $M E F V$ gene did not yield a second mutation in any of these cases (20). A recent study demonstrated that the frequency of FMF-like symptoms increased from patients carrying a single low penetrance mutation toward patients with two high-penetrance mutations suggesting a "dose effect" associated with mutations (37). One other explanation for heterozygote FMF patients may be the effect of the other modifier genes such as serum amyloid A (SAA) gene. $S A A$ polymorphisms have been shown to contribute the severity of FMF phenotype inducing the expression of pro-interleukin$1 \beta$ (IL-1 $\beta$ ) and activating NLRP3 inflammasome resulting in the secretion of active IL-1 $\beta(4,38)$. In the same lines, recently, Atoyan et al. have shown that SAA1 $\alpha$ allele was strongly associated with amyloidosis in FMF patients (39). On the other hand, environmental factors also have effect on the disease phenotype. Touitou et al. examined the characteristics of 2,482 FMF patients (260 of whom had amyloidosis) from 14 different countries (40). They demonstrated that the country of recruitment (roughly the same as the country of residence) was the most important determinant of amyloidosis risk.

We had shown that Turkish children with FMF in Germany expressed a less severe disease phenotype in comparison with the ones living in eastern Mediterranean (41). In addition, when we examined the Eurofever registry, we have seen that patients with a European ancestry have a milder disease than the Eastern Mediterranean patients (41). Furthermore, patients living in eastern Mediterranean countries had a higher frequency of fever episodes per year, and more frequent arthritis, pericarditis, chest pain, abdominal pain, and vomiting compared to the patients living in Western Europe (41). It was noteworthy that Western European patients had less frequent abdominal pain, pericarditis, and arthritis than eastern Mediterraneans (41). All of the above studies suggest the effect of environment on the phenotype of this monogenic disease.

Another issue that deserves a mention is autosomal dominant FMF.Differentmutations(H478Y,T577S, T577A, T577N, M694del, M694I, E148Q, and L110P) in MEFV have been reported to cause dominant FMF in patients from different populations; Spanish, Turkish, Dutch, British, Indian, and Japanese (18, 41-45). These reports have shown that FMF could also be inherited autosomal dominantly, and these patients may have different disease phenotypes. Rowczenio et al. reported that symptoms may develop later in life in autosomal dominant FMF with p.M694Vdel than in classical recessive FMF (45). Stoffels et al. have demonstrated that these patients may have different symptoms during attacks such as urticarial rash and conjunctivitis overlapping with other AID (18).

Although this is a monogenic disease, epigenetic factors and microbiota may play role in the pathogenesis of FMF or phenotypic expression. It is tempting to speculate that host-microbe interactions may be important in this innate immune system disease. Khachatryan et al. demonstrated that the composition and divergence of microbiota were different during attack and attack-free periods as well as between FMF patients and healthy controls (46).

\section{DISEASE PATHOGENESIS}

Pyrin, encoded by $M E F V$, has been suggested to interact with ASC (the inflammasome adaptor protein). The subsequent assembly of the inflammasome was suggested to activate caspase- 1 leading to the cleavage and activation of IL-1 $\beta$ (47).

Until recently, it was a debate whether the disease-causing mutations in the $M E F V$ gene were loss-of-function or gain-offunction mutations. There were different results depending on the different experimental settings. Supporting the loss-of-function model, Papin et al. demonstrated an increase in caspase- 1 activation and IL-1 $\beta$ secretion as a result of pyrin knockdown (48). Hesker et al. showed that in response to inflammatory stimuli in a mouse line lacking the $M E F V$ gene, IL- $1 \beta$ release by macrophages was enhanced (49).

On the other hand, in compliance with the gain-of-function model, Booty et al. demonstrated a significant increase in pyrin expression in FMF patients compared to healthy controls (20). $\mathrm{Yu}$ et al. have shown that activated pyrin forms a trimolecular complex by interacting with ASC and PTSPIP1, and this complex directly activates caspase- 1 and leads to secretion of IL-1 $\beta$ (50). In 2011, Chae et al. have demonstrated that homozygous knock-in mice with the mouse pyrin protein fused to the human B30.2 domain containing FMF-associated mutations secrete large amounts of IL-1 $\beta$ in an NLRP3-independent manner (51). These data confirmed that the mutations associated with FMF were gain-of-function mutations and suggested that FMF was a pyrin inflammasomopathy (51).

Almost 20 years after defining the genetic basis of FMF and learning the role of pyrin in its pathogenesis, we now have some new data elaborating the role of pyrin in pathogenesis $(12,52)$. The detection of pathogenic microorganisms by PRRs triggers the formation of inflammasome (53). Recent data suggest that pyrin is also a PRR (12).

Two major virulence factors of Clostridium difficile, namely, TcdA and $\operatorname{TcdB}(54,55)$ inactivate Rho GTPases via monoglycosylating a threonine residue in the GTPase switch I region of the protein (12). Recent studies have also shown that TcdB could trigger caspase- 1 activation and IL- $1 \beta$ production; thus, it can activate the inflammasome $(12,56,57)$. Furthermore, the $\mathrm{C} 3$ toxin of Clostridium botulinum and type VI secretion system 
(T6SS) of Burkholderia cenocepacia inactivate RHO by modifying the GTPase switch I region with different chemical groups and both trigger inflammasome activation (12). These results suggest that the bacterial toxins modifying RHO could trigger caspase-1 activation and IL-1 $\beta$ production; thus induce the inflammasome (12). The inflammasome activation by these toxins (TcdB, C3, and T6SS) was independent of NLRP3 and NLRC4 but was decreased in $\mathrm{ASC}^{-1-}$ and $\mathrm{MEFV}^{-/-}$bone marrow-derived macrophages (12). In addition, small interference RNA knockdown of pyrin inhibited TcdB-induced caspase- 1 activation (12). These results also support the "gain-of-function" model in the pathogenesis of FMF. Since different inhibiting modifications in RHO proteins all result in caspase- 1 activation, pyrin probably senses a downstream event in the actin cytoskeleton pathway (12).

The study by Park et al. has enlightened these mechanisms further (52). They have demonstrated that staurosporine, a potent inhibitor of protein kinase $\mathrm{C}$ that is an effector of RhoA, induced IL-1 $\beta$ release independent of the NLRP3, NLRC4, or AIM2 inflammasomes but dependent on the pyrin inflammasome (52). This shows that RhoA effector kinases suppress pyrin inflammasome activation. PKNs, RhoA effector kinases, bind to human pyrin and phosphorylate Ser208 and Ser242 units. The binding of PKN1 to the pyrin of FMF-knock-in mice (with B30.2 mutations; $\mathrm{Mefv}^{\mathrm{M} 680 \mathrm{I} / \mathrm{M} 680 \mathrm{I}}, \mathrm{Mefv}^{\mathrm{M} 694 \mathrm{~V} / \mathrm{M} 694 \mathrm{~V}}$, and Mefv $\left.{ }^{\mathrm{V} 726 \mathrm{~A} / \mathrm{V} 726 \mathrm{~A}}\right)$ was substantially decreased in comparison with the binding of PKN1 to wild type $\left(\mathrm{Mefv}^{+/+}\right)$mouse pyrin, which lacks a B30.2 orthologous domain (52). The binding of PKN1 to the pyrin of wild type B30.2 domain knock-in mice ( $\mathrm{Mefv}^{\mathrm{B} 30.2 / \mathrm{B} 30.2}$ ) was also decreased relative to wild-type mouse pyrin (but not as much as in FMF knock-in mice) (52). These suggest that the human B30.2 domain has a role in the regulation of PKN1 binding to pyrin. It was also shown that 14-3-3 protein binds to phospho-pyrin (phosphorylated from Ser208 and Ser242 units by PKNs) to inhibit inflammasome activation. Furthermore, the binding of 14-3-3 to mutant pyrin (M680I, M694V, and V726A) was decreased relative to wild-type human pyrin (52). All aforementioned results show that active RhoA signals through PKNs, which phosphorylate pyrin from Ser208 and Ser242 units. Then, 14-3-3 proteins bind to phosphopyrin and inhibit the activation of pyrin inflammasome. Pyrin is activated when dephosphorylated at Ser208/Ser242. The binding of PKN1 to pyrin is decreased with the B30.2 domain where most of the common and severe $M E F V$ mutations are clustered.

These data enlighten the effect of mutations on pyrin function and the downstream event of RhoA inhibiting pyrin. Active pyrin promotes ASC oligomerization and forms a caspase- 1 activating complex resulting in IL- $1 \beta$ production. Wild-type pyrin relies selectively on microtubules for inflammasome activation and microtubules control pyrin signaling downstream of pyrin dephosphorylation (52). Recently, Van Gorp et al. have observed that colchicine pretreatment augments the TcdA-induced IL- $1 \beta$ secretion from FMF peripheral blood mononuclear cells (58). The microtubule assembly inhibition with nocodazole also had the same effect. Thus, FMF-associated mutated pyrin does not require microtubules for ASC speck assembly. $M E F V$ mutations in B30.2 domain probably remove the critical reliance on intact microtubules for pyrin-based nucleation of ASC specks and inflammasome signaling (58).
To make the story even more complex, in a recent study, Kimura et al. have demonstrated that pyrin (referred as TRIM20 in the article) recognizes the inflammasome components, NLRP1, NLRP3, and procaspase-1 and leads to their autophagic degradation (59). Diminished autophagic degradation of NLRP3 was shown in single (M694V), double (M680I and M694V), and triple (M680I, M694V, and V726A) mutants (59).

When we look at the cellular level, we know that neutrophilia and influx of neutrophils to the inflamed sites occur in FMF attacks (60). Gohar et al. demonstrated that in vitro, unstimulated neutrophils from M694V positive patients spontaneously secreted more S100A12, IL-18, and caspase-1 compared to neutrophils from healthy controls (61). In another study, it has recently been shown that FMF attack is characterized by release of neutrophil extracellular traps (NET) including active IL-1 $\beta$ (60). These NET structures are observed in the first hours of FMF attacks, and subside as the inflammatory attack is resolved. They have demonstrated that NETs restrict their own generation by a negative feedback mechanism, which may be an explanation for the self-limited nature of FMF attacks. Of note, in this study, neutrophils from FMF patients in remission were resistant to induction of NET release. They have shown that reduced basal autophagy levels in these cells could be responsible for this since autophagy induction is needed for NET formation. Thus, lower basal autophagy levels of neutrophils may protect from attacks by attenuating the release of pro-inflammatory NETs.

Manukyan et al. have recently shown that the ex vivo spontaneous apoptotic rate of neutrophils from FMF patients in remission is significantly higher compared to control (62). The accelerated apoptosis of neutrophils in FMF may be important for successful resolution of inflammation and prevention of tissue damage. This may be another explanation for the self-limited nature of FMF attacks. Pyrin modulates the susceptibility to apoptosis; however, the effect of the mutant pyrin on apoptotic processes is poorly understood.

Although now we know more about the function of pyrin, the role of neutrophils, and the disease pathogenesis, there are still questions waiting to be answered such as the exact reason for the episodic and short-term nature of the inflammatory attacks and the phenotypic variability in FMF.

\section{TREATMENT}

Familial Mediterranean fever can be well controlled with optimum standard management. Recently, with the international collaboration of experienced experts from different countries, the European League Against Rheumatism (EULAR) recommendation set for the management of FMF has been published supported by the best available evidence (17). These recommendations are presented in Table 2.

The EULAR recommendations emphasize that the aim of FMF treatment is obtaining the control of acute attacks, minimizing the chronic and subclinical inflammation, preventing complications, and providing an acceptable quality of life.

It is also emphasized that colchicine is the main treatment of FMF since 1972 (63). It is generally a safe and well-tolerated drug, but its mechanism of action in FMF has not been completely 
TABLE 2 | The European League Against Rheumatism recommendations for the management of FMF with grade of recommendation [adapted from Ref. (17)].

\section{Recommendation}

Grade

01. Ideally, FMF should be diagnosed and initially treated by a physician with experience in FMF

02. The ultimate goal of treatment in FMF is to reach complete control of unprovoked attacks and minimizing subclinical inflammation in between attacks

03. Treatment with colchicine should start as soon as a clinical diagnosis is made

04. Dosing can be in single or divided doses, depending on tolerance and compliance

05. The persistence of attacks or of subclinical inflammation represents an indication to increase the colchicine dose

06. Compliant patients not responding to the maximum tolerated dose of colchicine can be considered non-respondent or resistant; alternative biological treatments are indicated in these patients

07. FMF treatment needs to be intensified in AA amyloidosis using the maximal tolerated dose of colchicine and supplemented with biologics as required

08. Periods of physical or emotional stress can trigger FMF attacks, and it may be appropriate to increase the dose of colchicine temporarily

09. Response, toxicity, and compliance should be monitored every 6 months

10. Liver enzymes should be monitored regularly in patients with FMF treated with colchicine; if liver enzymes are elevated greater than twofold the upper limit of normal, colchicine should be reduced and the cause further investigated

11. In patients with decreased renal function, the risk of toxicity is very high, and therefore signs of colchicine toxicity, as well as CPK, should be carefully monitored and colchicine dose reduced accordingly

12. Colchicine toxicity is a serious complication and should be adequately suspected and prevented

13. When suspecting an attack, always consider other possible causes. During the attacks, continue the usual dose of colchicine and use NSAID

14. Colchicine should not be discontinued during conception, pregnancy, or lactation; current evidence does not justify amniocentesis

15. In general, men do not need to stop colchicine prior to conception; in the rare case of azoospermia or oligospermia proven to be related to colchicine, temporary dose reduction or discontinuation may be needed

16. Chronic arthritis in a patient with FMF might need additional medications, such as DMARDs, intra-articular steroid injections, or biologics

17. In protracted febrile myalgia, glucocorticoids lead to the resolution of symptoms; NSAID and IL-1-blockade might also be a treatment option; NSAIDs are suggested for the treatment of exertional leg pain

18. If a patient is stable with no attacks for more than 5 years and no elevated APR, dose reduction could be considered after expert consultation and with continued monitoring

APR, acute phase reactants; CPK, creatinine phosphokinase; DMARDs, diseasemodifying antirheumatic drugs; FMF, familial Mediterranean fever; IL-1, interleukin-1; NSAID, non-steroidal anti-inflammatory drugs.

elucidated. However, we know that it prevents microtubule elongation by binding to tubulin monomers and inhibiting polymer formation $(64,65)$. Thus, the link between pyrin and colchicine could be through the organization of actin cytoskeleton.

Previously, it was claimed that colchicine is an activator of RhoA (66). It binds to tubulin, depolymerizes microtubules and causes release of the RhoA activator guanine-nucleotide-exchange factor-H1, which is inactive when bound to microtubules (66). Park et al. demonstrated that colchicine inhibited the constitutive IL-1 $\beta$ release from bone-marrow-derived macrophages (BMDMs) of Mefv ${ }^{\mathrm{V} 726 \mathrm{~A} / \mathrm{V} 726 \mathrm{~A}}$ mice and C3-toxin-induced IL-1 $\beta$ release from primed BMDMs. In addition, colchicine inhibited IL-1 $\beta$ release from PBMCs of FMF patients (52). In the same lines, Van Gorp et al. demonstrated that microtubule-depolymerizing drugs selectively inhibited the pyrin inflammasome (58). Thus, colchicine may be inhibiting pyrin inflammasome through RhoA activation by releasing RhoA activator from depolymerized microtubules.

Certain other pharmacological anti-inflammatory effects of colchicine have been enlightened such as preventing activation of neutrophils by forming $\beta$-tubulin-colchicine complexes and inhibiting the microtubule assembly and mitotic spindle formation, suppressing caspase- 1 gene expression, and inhibiting the synthesis of tumor necrosis factor alpha (TNF- $\alpha)(65,67-70)$.

It is suggested that colchicine should be started as soon as the patient is clinically diagnosed as having FMF. If the patient lacks clinical manifestations or subclinical inflammation, genetic diagnosis is not a precise indication to start treatment; however, these patients should be followed-up closely for clinical symptoms or signs of subclinical inflammation (17). In countries where amyloidosis has high frequency, the physician may consider treatment in these patients especially when the patient has homozygous M694V mutation, which is more frequently associated with the development of amyloidosis $(9,21,71-77)$.

The optimal dosage of colchicine varies between studies and different clinical practices. The recommendation of the starting dose of colchicine in FMF is $\leq 0.5 \mathrm{mg} /$ day for children $<5$ years of age; $0.5-1 \mathrm{mg} /$ day for children $5-10$ years of age; and $1-1.5 \mathrm{mg}$ /day in children $>10$ years of age and in adults (in case tablet contains $0.6 \mathrm{mg}$; $\leq 0.6 \mathrm{mg} /$ day; $1.2 \mathrm{mg} /$ day; and $1.8 \mathrm{mg} /$ day, respectively) (17). Higher starting doses could be used in patients with high disease activity or disease complications such as amyloidosis (17). However, in most patients, it is started at the subtherapeutic dose of $0.5 \mathrm{mg} /$ day and adjusted according to disease activity and tolerance in the follow-up. While escalating colchicine dose in patients with active disease, monitoring C-reactive protein (CRP) and SAA, or both is required at least every 3 months (17). Both increase in attack frequency and presence of subclinical inflammation are indications to increase colchicine dose. The maximum dose is $2 \mathrm{mg} / \mathrm{day}$ in children and $3 \mathrm{mg} /$ day in adults $(14,78)$. Dosing can be in single or divided doses. The dose can be divided to decrease side effects; however, a single daily dose may increase the compliance (17). Polat et al. have recently shown that using colchicine with either once- or twice-daily dosage provides similar clinical and laboratory improvement as well as the similar rate of drug side effect (79).

Colchicine treatment is lifelong in FMF. However, in EULAR recommendations, FMF experts recommend the consideration of colchicine dose reduction by an experienced center under certain circumstances with very careful and close follow-up (17).

Colchicine is a safe drug in the range of doses used for FMF treatment (80). The most common side effects of the drug and toxicity are also reviewed in the aforementioned recommendations. The most common side effect is gastrointestinal disturbance, which may be seen in up to $10 \%$ of patients during the 
first month of the treatment $(81,82)$. It was shown that jejunal lactase, sucrase, and maltase activities decreased in patients on long-term colchicine treatment (83). In these patients, increased fecal excretion of starch, fat, and bile acids and decreased absorption of D-xylose and vitamin B12 occur, as well. These may be the explanation for diarrhea and lactose intolerance, and a symptomatic relief can be provided with a lactose-free diet $(83,84)$. Dose reduction may also improve the gastrointestinal symptoms (85). There are also some rare side effects of colchicine, such as vitamin B12 deficiency, reversible peripheral neuritis and myopathy, bone marrow suppression, and alopecia (86-89). In addition, some animal studies and case reports suggested its association with azoospermia $(90,91)$; however, this was only in very high doses. Thus, in general, men need not stop colchicine prior to conception (17). Colchicine use is safe during pregnancy and lactation, as well (92-94). However, it should be used cautiously in patients with impaired renal or hepatic functions (95).

Compliance with colchicine is very important for proper management of FMF. One study showed that proteinuria that is usually the first sign of renal amyloidosis, developed after a period of $9-11$ years in $1.7 \%$ of 960 adult patients who properly used colchicine versus $49 \%$ in 54 patients who were not compliant (96). There is a surprisingly high rate of incompliance with colchicine especially among adolescent patient (17). Thus, in the case of patients not responding to colchicine, the physician should keep in mind the possibility of incompliance. Overall, up to $5 \%$ of FMF patients may not respond to colchicine treatment and another $2-5 \%$ is colchicine intolerant (85).

Anti-IL-1 therapy seems to be a promising second-line therapy in refractory or intolerant patients. However, one should keep in mind that colchicine should be coadministered with biologic therapies since it may reduce the risk of amyloidosis (17). There are three types of anti-IL-1 agents in clinical use; anakinra, a recombinant homolog of the human IL-1 receptor (97); canakinumab, a fully human immunoglobulin G1 monoclonal antibody (98); and rilonacept, a dimeric Fc-fusion protein capturing IL-1 (97); all administered subcutaneously.

The most recent systematic review of the literature (99) has yielded 24 case reports/series, 2 open-label prospective trials $(100,101)$, and 1 placebo-controlled prospective trial (102) on anti-IL-1 use in FMF. Eighteen reports were on treatment with anakinra (103-120), four on canakinumab (100, 101, 121, 122), four on patients treated with either anakinra or canakinumab (123-126), and the only placebo-controlled prospective trial was on treatment with rilonacept (102). A complete response to therapy was reported in $76.5 \%$ of patients on anakinra, and $67.5 \%$ of patients on canakinumab treatment (99). In addition, IL-1 blockade can reverse proteinuria in patients with renal AA amyloidosis $(99,127)$. However, we do not know whether anti-IL-1 therapies could prevent amyloidosis. A new study on efficacy/safety of canakinumab in patients with hereditary periodic fevers including FMF is also underway (http://ClinicalTrials. gov identifier NCT02059291).

Anti-IL-1 drugs may be used "on demand" (starting at first symptom of attacks) in mevalonate kinase deficiency (128). We need further data on whether this would be an option for selected cases in FMF or on certain occasions.
Besides IL-1 blockade, FMF patients with chronic arthritis and/or sacroiliitis could benefit from disease-modifying antirheumatic drugs or anti-TNF agents $(129,130)$.

Treatment of protracted febrile myalgia syndrome (PFMS) has also been addressed. PFMS is a very rare manifestation of FMF and is defined as severe, disabling myalgia of at least 5 days duration $(108,112)$. It is associated with fever, the presence of at least one M694V mutation, and elevated inflammatory markers while creatine kinase levels are usually normal $(131,132)$. Corticosteroid treatment is required to suppress symptoms (17, $131,133,134)$. Non-steroidal anti-inflammatory drugs may also be beneficial (131). In addition, anakinra has been used successfully in two patients with PFMS associated with FMF (112).

\section{Treatment in Heterozygotes}

Familial Mediterranean fever is a clinical diagnosis, and we have many patients who are heterozygous for $M E F V$ mutations. How patients with one mutation only can express the disease is still not clear (135). We give colchicine treatment to patients who express the typical FMF phenotype. However, some heterozygotes can sometimes "outgrow" the phenotype (30). Ben-Zvi et al. previously demonstrated that their patients (not using colchicine) experienced years of symptom-free interval where 22 out of these 33 were heterozygotes (136).

The data on remission of the disease in heterozygotes are limited. Recently, we have reported our experience on heterozygote patients with transient FMF clinic (7). We discontinued colchicine treatment in 22 heterozygote FMF patients who had an inflammation- and attack-free period for a long duration. The median follow-up after colchicine cessation was 22.5 months, and we restarted colchicine in only two patients because of the recurrence of attacks. However, after colchicine cessation, close follow-up is crucial every 3-6 months to evaluate whether they have recurrence of attacks or subclinical inflammation.

\section{Refractory FMF and Outcome}

There is no standard definition for refractory FMF patients. However, in the recent guideline, we stated that patients who continue to have $\geq 1$ attacks per month despite receiving the maximally tolerated dose for $\geq 6$ months might be considered non-responder or resistant to colchicine (17). Another issue is ongoing subclinical inflammation, which leaves the patients at risk of developing amyloidosis (17). In addition, in the case of AA amyloidosis, the FMF treatment should be intensified with biologics and maximal tolerated dose of colchicine (17).

There are mainly two tools to evaluate outcome and disease activity in FMF; FMF50 score and autoinflammatory disease activity index, respectively.

In FMF50, the items are percentage change in the frequency and duration of attacks, arthritis attacks, physician's and patient's/ parents' global assessment of disease severity $(0-10 \mathrm{~cm}$ visual analog scale; 10 the worst), and in ESR, CRP, or SAA level with the treatment (137). At least 50\% improvement in five out of six criteria by 3 -6 months with no worsening in any one means FMF50 response. It is noteworthy that compliance with the maximum dose of drug is essential for evaluating the patients with FMF50 score. 
Autoinflammatory disease activity index is a disease activity assessment tool for AID including FMF, and it is composed of 13 items: overall symptoms, nausea/vomiting, abdominal pain, diarrhea, chest pain, arthralgia or myalgia, swelling of the joints, headaches, eye manifestations, skin rash, and pain relief (138). Each item except pain relief is scored by the patients/parents for a total score of $0-34$ in a single day and $0-1,054$ in a month of 31 days. A cutoff score of $\geq 9$ discriminates active from inactive patients with a sensitivity of $89 \%$ and specificity of $92 \%$ (138).

There is also one recent tool for AID including FMF to quantify damage in patients and to compare disease outcomes in clinical studies; autoinflammatory disease damage index (ADDI) (139).

In ADDI, damage is defined as "persistent or irreversible change in structure or function that is present for at least 6 months" (139). ADDI contains 18 items, and these items are categorized by organ systems as follows: reproductive, renal/amyloidosis, developmental, serosal, neurological, ears, ocular, and musculoskeletal. The renal/amyloidosis and neurological damage categories were assigned to have the highest number of points while serosal damage got the lowest. This index provides a universal instrument to measure damage by chronic inflammation in FMF.

These tools could aid us to form a standard definition for refractory FMF patients and standardize the outcome measurement in different studies.

\section{UNSOLVED ISSUES IN FMF}

As we mentioned above in the relevant parts, there are still gaps in knowledge about the pathogenesis and treatment mechanisms in FMF. We need further research on the following:

- the significance of the E148Q variant,

- exact roles of modifier factors (microbiota, microRNAs, etc.) on disease pathogenesis, phenotypic expression, and severity of the disease,

\section{REFERENCES}

1. Daniels M, Shohat T, Brenner-Ullman A, Shohat M. Familial Mediterranean fever: high gene frequency among the non-Ashkenazic and Ashkenazic Jewish populations in Israel. Am J Med Genet (1995) 55(3):311-4. doi:10.1002/ ajmg.1320550313

2. Ozen S, Karaaslan Y, Ozdemir O, Saatci U, Bakkaloglu A, Koroglu E, et al. Prevalence of juvenile chronic arthritis and familial Mediterranean fever in Turkey: a field study. J Rheumatol (1998) 25(12):2445-9.

3. Kishida D, Nakamura A, Yazaki M, Tsuchiya-Suzuki A, Matsuda M, Ikeda SI. Genotype-phenotype correlation in Japanese patients with familial Mediterranean fever: differences in genotype and clinical features between Japanese and Mediterranean populations. Arthritis Res Ther (2014) 16(5):439. doi:10.1186/s13075-014-0439-7

4. Migita K, Agematsu K, Masumoto J, Ida H, Honda S, Jiuchi Y, et al. The contribution of SAA1 polymorphisms to familial Mediterranean fever susceptibility in the Japanese population. PLoS One (2013) 8(2):e55227. doi:10.1371/journal.pone.0055227

5. Tunca M, Akar S, Onen F, Ozdogan H, Kasapcopur O, Yalcinkaya F, et al. Familial Mediterranean fever (FMF) in Turkey: results of a nationwide multicenter study. Medicine (2005) 84(1):1-11. doi:10.1097/01.md.0000152370. 84628.0c

6. Twig G, Livneh A, Vivante A, Afek A, Shamiss A, Derazne E, et al. Mortality risk factors associated with familial Mediterranean fever among a cohort of
- the effects of mutant pyrin on apoptosis,

- the exact reason for the self-limited and episodic nature of disease attacks,

- whether anti-IL-1 treatment prevents amyloidosis,

- the definition of colchicine resistance,

- why certain rheumatic diseases are more common in heterozygotes, and why they sometimes express the disease phenotype,

- the duration of treatment in heterozygous patients,

- more biomarkers for secondary amyloidosis.

\section{CONCLUSION}

When the mutated protein for FMF was described 20 years ago, we thought that everything was resolved. However, this monogenic disease continues to be of interest to clinical and basic researchers. We still need to address the above questions and the cause of the phenotypic heterogeneity in this disease. On the other hand, the experts on FMF have worked on compiling recommendations to guide physicians in the diagnosis, management, and treatment of FMF. It is hoped that these recommendations may be of practical use while the work on solving the pathogenesis continue.

\section{AUTHOR CONTRIBUTIONS}

EB and SD prepared the first draft of the article. SÖ made the critical revision of the article. All the authors have seen and approved the final version of the manuscript.

\section{SUPPLEMENTARY MATERIAL}

The Supplementary Material for this article can be found online at http://journal.frontiersin.org/article/10.3389/fimmu. 2017.00253/full\#supplementary-material.

1.25 million adolescents. Ann Rheum Dis (2014) 73(4):704-9. doi:10.1136/ annrheumdis-2012-202932

7. Sonmez HE, Batu ED, Bilginer Y, Ozen S. Discontinuing colchicine in symptomatic carriers for MEFV (Mediterranean FeVer) variants. Clin Rheumatol (2016) 36(2):421-5. doi:10.1007/s10067-016-3421-8

8. Giancane G, Ter Haar N, Wulffraat N, Vastert B, Barron K, Hentgen V, et al. Evidence based recommendations for genetic diagnosis of familial Mediterranean fever. Pediatr Rheumatol Online J (2014) 12(Suppl 1):241. doi:10.1186/1546-0096-12-S1-P241

9. Aksentijevich I, Centola M, Deng Z, Sood R, Balow JE, Wood G, et al. Ancient missense mutations in a new member of the RoRet gene family are likely to cause familial Mediterranean fever. The International FMF Consortium. Cell (1997) 90(4):797-807. doi:10.1016/S0092-8674(00) 80539-5

10. French FMFC. A candidate gene for familial Mediterranean fever. Nat Genet (1997) 17(1):25-31. doi:10.1038/ng0997-25

11. Berkun Y, Padeh S, Reichman B, Zaks N, Rabinovich E, Lidar M, et al. A single testing of serum amyloid a levels as a tool for diagnosis and treatment dilemmas in familial Mediterranean fever. Semin Arthritis Rheum (2007) 37(3):182-8. doi:10.1016/j.semarthrit.2007. 03.005

12. Xu H, Yang J, Gao W, Li L, Li P, Zhang L, et al. Innate immune sensing of bacterial modifications of Rho GTPases by the pyrin inflammasome. Nature (2014) 513(7517):237-41. doi:10.1038/nature13449 
13. Majeed HA, Rawashdeh M, el-Shanti H, Qubain H, Khuri-Bulos N, Shahin HM. Familial Mediterranean fever in children: the expanded clinical profile. QJM (1999) 92(6):309-18. doi:10.1093/qjmed/92.6.309

14. Zemer D, Livneh A, Danon YL, Pras M, Sohar E. Long-term colchicine treatment in children with familial Mediterranean fever. Arthritis Rheum (1991) 34(8):973-7. doi:10.1002/art.1780340806

15. Livneh A, Langevitz P. Diagnostic and treatment concerns in familial Mediterranean fever. Baillieres Best Pract Res Clin Rheumatol (2000) 14(3):477-98. doi:10.1053/berh.2000.0089

16. Ben-Zvi I, Livneh A. Colchicine failure in familial Mediterranean fever and potential alternatives: embarking on the anakinra trial. Isr Med Assoc J (2014) 16(5):271-3.

17. Ozen S, Demirkaya E, Erer B, Livneh A, Ben-Chetrit E, Giancane G, et al. EULAR recommendations for the management of familial Mediterranean fever. Ann Rheum Dis (2016) 75(4):644-51. doi:10.1136/ annrheumdis-2015-208690

18. Stoffels M, Szperl A, Simon A, Netea MG, Plantinga TS, van Deuren M, et al. MEFV mutations affecting pyrin amino acid 577 cause autosomal dominant autoinflammatory disease. Ann Rheum Dis (2014) 73(2):455-61. doi:10.1136/ annrheumdis-2012-202580

19. Balow JE Jr, Shelton DA, Orsborn A, Mangelsdorf M, Aksentijevich I, Blake $\mathrm{T}$, et al. A high-resolution genetic map of the familial Mediterranean fever candidate region allows identification of haplotype-sharing among ethnic groups. Genomics (1997) 44(3):280-91. doi:10.1006/geno.1997.4860

20. Booty MG, Chae JJ, Masters SL, Remmers EF, Barham B, Le JM, et al. Familial Mediterranean fever with a single MEFV mutation: where is the second hit? Arthritis Rheum (2009) 60(6):1851-61. doi:10.1002/art.24569

21. Shinar Y, Obici L, Aksentijevich I, Bennetts B, Austrup F, Ceccherini I, et al. Guidelines for the genetic diagnosis of hereditary recurrent fevers. Ann Rheum Dis (2012) 71(10):1599-605. doi:10.1136/annrheumdis-2011201271

22. Moradian MM, Sarkisian T, Ajrapetyan H, Avanesian N. Genotype-phenotype studies in a large cohort of Armenian patients with familial Mediterranean fever suggest clinical disease with heterozygous MEFV mutations. J Hum Genet (2010) 55(6):389-93. doi:10.1038/jhg.2010.52

23. Sarkisian T, Ajrapetyan H, Shahsuvaryan G. Molecular study of FMF patients in Armenia. Curr Drug Targets Inflamm Allergy (2005) 4(1):113-6. doi:10.2174/1568010053622885

24. El-ShantiH, MajeedHA,El-Khateeb M. Familial Mediterranean fever in Arabs. Lancet (2006) 367(9515):1016-24. doi:10.1016/S0140-6736(06)68430-4

25. Padeh S, Shinar Y, Pras E, Zemer D, Langevitz P, Pras M, et al. Clinical and diagnostic value of genetic testing in 216 Israeli children with familial Mediterranean fever. J Rheumatol (2003) 30(1):185-90.

26. Majeed HA, El-Shanti H, Al-Khateeb MS, Rabaiha ZA. Genotype/phenotype correlations in Arab patients with familial Mediterranean fever. Semin Arthritis Rheum (2002) 31(6):371-6. doi:10.1053/sarh.2002.32551

27. Ben-Chetrit E, Lerer I, Malamud E, Domingo C, Abeliovich D. The E148Q mutation in the MEFV gene: is it a disease-causing mutation or a sequence variant? Hum Mutat (2000) 15(4):385-6. doi:10.1002/ (SICI) 1098-1004(200004)15:4<385:AID-HUMU22>3.0.CO;2-A

28. Aksentijevich I, Torosyan Y, Samuels J, Centola M, Pras E, Chae JJ, et al. Mutation and haplotype studies of familial Mediterranean fever reveal new ancestral relationships and evidence for a high carrier frequency with reduced penetrance in the Ashkenazi Jewish population. Am J Hum Genet (1999) 64(4):949-62. doi:10.1086/302327

29. Bernot A, da Silva C, Petit JL, Cruaud C, Caloustian C, Castet V, et al. Nonfounder mutations in the MEFV gene establish this gene as the cause of familial Mediterranean fever (FMF). Hum Mol Genet (1998) 7(8):1317-25. doi:10.1093/hmg/7.8.1317

30. Ozen S, Batu ED. The myths we believed in familial Mediterranean fever: what have we learned in the past years? Semin Immunopathol (2015) 37(4):363-9. doi:10.1007/s00281-015-0484-6

31. Tchernitchko D, Legendre M, Cazeneuve C, Delahaye A, Niel F, Amselem $\mathrm{S}$. The E148Q MEFV allele is not implicated in the development of familial Mediterranean fever. Hum Mutat (2003) 22(4):339-40. doi:10.1002/ humu.9182

32. Topaloglu R, Ozaltin F, Yilmaz E, Ozen S, Balci B, Besbas N, et al. E148Q is a disease-causing MEFV mutation: a phenotypic evaluation in patients with familial Mediterranean fever. Ann Rheum Dis (2005) 64(5):750-2. doi:10.1136/ard.2004.026963

33. Yilmaz E, Ozen S, Balci B, Duzova A, Topaloglu R, Besbas N, et al. Mutation frequency of familial Mediterranean fever and evidence for a high carrier rate in the Turkish population. Eur J Hum Genet (2001) 9(7):553-5. doi:10.1038/ sj.ejhg. 5200674

34. Topaloglu R, Batu ED, Yildiz C, Korkmaz E, Ozen S, Besbas N, et al. Familial Mediterranean fever patients homozygous for E148Q variant. Int J Rheum Dis (2016). doi:10.1111/1756-185X.12929

35. Cazeneuve C, Hovannesyan Z, Genevieve D, Hayrapetyan H, Papin S, Girodon-Boulandet E, et al. Familial Mediterranean fever among patients from Karabakh and the diagnostic value of MEFV gene analysis in all classically affected populations. Arthritis Rheum (2003) 48(8):2324-31. doi:10.1002/art.11102

36. Marek-Yagel D, Berkun Y, Padeh S, Abu A, Reznik-Wolf H, Livneh A, et al. Clinical disease among patients heterozygous for familial Mediterranean fever. Arthritis Rheum (2009) 60(6):1862-6. doi:10.1002/art.24570

37. Federici S, Calcagno G, Finetti M, Gallizzi R, Meini A, Vitale A, et al. Clinical impact of MEFV mutations in children with periodic fever in a prevalent western European Caucasian population. Ann Rheum Dis (2012) 71(12):1961-5. doi:10.1136/annrheumdis-2011-200977

38. Niemi K, Teirila L, Lappalainen J, Rajamaki K, Baumann MH, Oorni K, et al. Serum amyloid A activates the NLRP3 inflammasome via P2X7 receptor and a cathepsin B-sensitive pathway. J Immunol (2011) 186(11):6119-28. doi:10.4049/jimmunol.1002843

39. Atoyan S, Hayrapetyan H, Sarkisian T, Ben-Chetrit E. MEFV and SAAl genotype associations with clinical features of familial Mediterranean fever and amyloidosis in Armenia. Clin Exp Rheumatol (2016) 34(6 Suppl 102):72-6.

40. Touitou I, Sarkisian T, Medlej-Hashim M, Tunca M, Livneh A, Cattan D, et al. Country as the primary risk factor for renal amyloidosis in familial Mediterranean fever. Arthritis Rheum (2007) 56(5):1706-12. doi:10.1002/ art. 22507

41. Ozen S, Demirkaya E, Amaryan G, Kone-Paut I, Polat A, Woo P, et al. Results from a multicentre international registry of familial Mediterranean fever: impact of environment on the expression of a monogenic disease in children. Ann Rheum Dis (2014) 73(4):662-7. doi:10.1136/annrheumdis-2012202708

42. Aldea A, Campistol JM, Arostegui JI, Rius J, Maso M, Vives J, et al. A severe autosomal-dominant periodic inflammatory disorder with renal AA amyloidosis and colchicine resistance associated to the MEFV H478Y variant in a Spanish kindred: an unusual familial Mediterranean fever phenotype or another MEFV-associated periodic inflammatory disorder? Am J Med Genet A (2004) 124A(1):67-73. doi:10.1002/ajmg.a.20296

43. Booth DR, Gillmore JD, Lachmann HJ, Booth SE, Bybee A, Soyturk M, et al. The genetic basis of autosomal dominant familial Mediterranean fever. QJM (2000) 93(4):217-21. doi:10.1093/qjmed/93.4.217

44. Fukushima Y, Obara K, Hirata H, Sugiyama K, Fukuda T, Takabe K. Three Japanese patients (mother and two children) with familial Mediterranean fever associated with compound heterozygosity for L110P/E148Q/M694I and an autosomal true dominant inheritance pattern. Asian Pac J Allergy Immunol (2013) 31(4):325-9. doi:10.12932/AP0244.31.4.2013

45. Rowczenio DM, Iancu DS, Trojer H, Gilbertson JA, Gillmore JD, Wechalekar $\mathrm{AD}$, et al. Autosomal dominant familial Mediterranean fever in Northern European Caucasians associated with deletion of p.M694 residue-a case series and genetic exploration. Rheumatology (2016) 56(2):209-13. doi:10.1093/ rheumatology/kew058

46. Khachatryan ZA, Ktsoyan ZA, Manukyan GP, Kelly D, Ghazaryan KA, Aminov RI. Predominant role of host genetics in controlling the composition of gut microbiota. PLoS One (2008) 3(8):e3064. doi:10.1371/journal. pone. 0003064

47. Park H, Bourla AB, Kastner DL, Colbert RA, Siegel RM. Lighting the fires within: the cell biology of autoinflammatory diseases. Nat Rev Immunol (2012) 12(8):570-80. doi:10.1038/nri3261

48. Papin S, Cuenin S, Agostini L, Martinon F, Werner S, Beer HD, et al. The SPRY domain of pyrin, mutated in familial Mediterranean fever patients, interacts with inflammasome components and inhibits proILlbeta processing. Cell Death Differ (2007) 14(8):1457-66. doi:10.1038/ sj.cdd. 4402142 
49. Hesker PR, Nguyen M, Kovarova M, Ting JP, Koller BH. Genetic loss of murine pyrin, the familial Mediterranean fever protein, increases interleukin-1beta levels. PLoS One (2012) 7(11):e51105. doi:10.1371/journal.pone. 0051105

50. Yu JW, Fernandes-Alnemri T, Datta P, Wu J, Juliana C, Solorzano L, et al. Pyrin activates the ASC pyroptosome in response to engagement by autoinflammatory PSTPIP1 mutants. Mol Cell (2007) 28(2):214-27. doi:10.1016/j. molcel.2007.08.029

51. Chae JJ, Cho YH, Lee GS, Cheng J, Liu PP, Feigenbaum L, et al. Gain-offunction pyrin mutations induce NLRP3 protein-independent interleukin-1beta activation and severe autoinflammation in mice. Immunity (2011) 34(5):755-68. doi:10.1016/j.immuni.2011.02.020

52. Park YH, Wood G, Kastner DL, Chae JJ. Pyrin inflammasome activation and RhoA signaling in the autoinflammatory diseases FMF and HIDS. Nat Immunol (2016) 17(8):914-21. doi:10.1038/ni.3457

53. Kamada N, Seo SU, Chen GY, Nunez G. Role of the gut microbiota in immunity and inflammatory disease. Nat Rev Immunol (2013) 13(5):321-35. doi: $10.1038 /$ nri3430

54. Kuehne SA, Cartman ST, Heap JT, Kelly ML, Cockayne A, Minton NP. The role of toxin A and toxin B in Clostridium difficile infection. Nature (2010) 467(7316):711-3. doi:10.1038/nature09397

55. Lyras D, O'Connor JR, Howarth PM, Sambol SP, Carter GP, Phumoonna T, et al. Toxin B is essential for virulence of Clostridium difficile. Nature (2009) 458(7242):1176-9. doi:10.1038/nature07822

56. Kayagaki N, Warming S, Lamkanfi M, Vande Walle L, Louie S, Dong J, et al. Non-canonical inflammasome activation targets caspase-11. Nature (2011) 479(7371):117-21. doi:10.1038/nature10558

57. Ng J, Hirota SA, Gross O, Li Y, Ulke-Lemee A, Potentier MS, et al. Clostridium difficile toxin-induced inflammation and intestinal injury are mediated by the inflammasome. Gastroenterology (2010) 139(2):e1-3. doi:10.1053/j. gastro.2010.04.005

58. Van Gorp H, Saavedra PH, de Vasconcelos NM, Van Opdenbosch N, Vande Walle L, Matusiak M, et al. Familial Mediterranean fever mutations lift the obligatory requirement for microtubules in pyrin inflammasome activation. Proc Natl Acad Sci U S A (2016) 113(50):14384-9. doi:10.1073/ pnas. 1613156113

59. Kimura T, Jain A, Choi SW, Mandell MA, Schroder K, Johansen T, et al. TRIM-mediated precision autophagy targets cytoplasmic regulators of innate immunity. J Cell Biol (2015) 210(6):973-89. doi:10.1083/jcb.201503023

60. Apostolidou E, Skendros P, Kambas K, Mitroulis I, Konstantinidis T, Chrysanthopoulou A, et al. Neutrophil extracellular traps regulate IL-1betamediated inflammation in familial Mediterranean fever. Ann Rheum Dis (2016) 75(1):269-77. doi:10.1136/annrheumdis-2014-205958

61. Gohar F, Orak B, Kallinich T, Jeske M, Lieber M, von Bernuth H, et al. Correlation of secretory activity of neutrophils with genotype in patients with familial Mediterranean fever. Arthritis Rheumatol (2016) 68(12):3010-22. doi:10.1002/art.39784

62. Manukyan G, Aminov R, Hakobyan G, Davtyan T. Accelerated apoptosis of neutrophils in familial Mediterranean fever. Front Immunol (2015) 6:239. doi:10.3389/fimmu.2015.00239

63. Goldfinger SE. Colchicine for familial Mediterranean fever. $N$ Engl J Med (1972) 287(25):1302. doi:10.1056/NEJM197212212872514

64. Ravelli RB, Gigant B, Curmi PA, Jourdain I, Lachkar S, Sobel A, et al. Insight into tubulin regulation from a complex with colchicine and a stathmin-like domain. Nature (2004) 428(6979):198-202. doi:10.1038/nature02393

65. Taskiran EZ, Cetinkaya A, Balci-Peynircioglu B, Akkaya YZ, Yilmaz E. The effect of colchicine on pyrin and pyrin interacting proteins. J Cell Biochem (2012) 113(11):3536-46. doi:10.1002/jcb.24231

66. Krendel M, Zenke FT, Bokoch GM. Nucleotide exchange factor GEF-H1 mediates cross-talk between microtubules and the actin cytoskeleton. Nat Cell Biol (2002) 4(4):294-301. doi:10.1038/ncb773

67. Ben-Chetrit E, Bergmann S, Sood R. Mechanism of the anti-inflammatory effect of colchicine in rheumatic diseases: a possible new outlook through microarray analysis. Rheumatology (2006) 45(3):274-82. doi:10.1093/ rheumatology/kei140

68. Cerquaglia C, Diaco M, Nucera G, La Regina M, Montalto M, Manna R. Pharmacological and clinical basis of treatment of familial Mediterranean fever (FMF) with colchicine or analogues: an update. Curr Drug Targets Inflamm Allergy (2005) 4(1):117-24. doi:10.2174/1568010053622984
69. Cronstein BN, Terkeltaub R. The inflammatory process of gout and its treatment. Arthritis Res Ther (2006) 8(Suppl 1):S3. doi:10.1186/ar1908

70. Manukyan G, Petrek M, Tomankova T, Martirosyan A, Tatyan M, Navratilova $\mathrm{Z}$, et al. Colchicine modulates expression of pro-inflammatory genes in neutrophils from patients with familial Mediterranean fever and healthy subjects. J Biol Regul Homeost Agents (2013) 27(2):329-36.

71. Ben-Chetrit E, Backenroth R. Amyloidosis induced, end stage renal disease in patients with familial Mediterranean fever is highly associated with point mutations in the MEFV gene. Ann Rheum Dis (2001) 60(2):146-9. doi:10.1136/ard.60.2.146

72. Cazeneuve C, Sarkisian T, Pecheux C, Dervichian M, Nedelec B, Reinert P, et al. MEFV-gene analysis in armenian patients with familial Mediterranean fever: diagnostic value and unfavorable renal prognosis of the M694V homozygous genotype-genetic and therapeutic implications. Am J Hum Genet (1999) 65(1):88-97. doi:10.1086/302459

73. Gershoni-Baruch R, Brik R, Zacks N, Shinawi M, Lidar M, Livneh A. The contribution of genotypes at the MEFV and SAA1 loci to amyloidosis and disease severity in patients with familial Mediterranean fever. Arthritis Rheum (2003) 48(4):1149-55. doi:10.1002/art.10944

74. Livneh A, Langevitz P, Shinar Y,Zaks N, Kastner DL, Pras M, etal. MEFV mutation analysis in patients suffering from amyloidosis of familial Mediterranean fever. Amyloid (1999) 6(1):1-6. doi:10.3109/13506129908993281

75. Medlej-Hashim M, Delague V, Chouery E, Salem N, Rawashdeh M, Lefranc G, et al. Amyloidosis in familial Mediterranean fever patients: correlation with MEFV genotype and SAA1 and MICA polymorphisms effects. BMC Med Genet (2004) 5:4. doi:10.1186/1471-2350-5-4

76. Mimouni A, Magal N, Stoffman N, Shohat T, Minasian A, Krasnov M, et al. Familial Mediterranean fever: effects of genotype and ethnicity on inflammatory attacks and amyloidosis. Pediatrics (2000) 105(5):E70. doi:10.1542/peds.105.5.e70

77. Shohat M, Magal N, Shohat T, Chen X, Dagan T, Mimouni A, et al. Phenotype-genotype correlation in familial Mediterranean fever: evidence for an association between Met694Val and amyloidosis. Eur J Hum Genet (1999) 7(3):287-92. doi:10.1038/sj.ejhg.5200303

78. Hentgen V, Grateau G, Kone-Paut I, Livneh A, Padeh S, Rozenbaum M, et al. Evidence-based recommendations for the practical management of familial Mediterranean fever. Semin Arthritis Rheum (2013) 43(3):387-91. doi:10.1016/j.semarthrit.2013.04.011

79. Polat A, Acikel C, Sozeri B, Dursun I, Kasapcopur O, Gulez N, et al. Comparison of the efficacy of once- and twice-daily colchicine dosage in pediatric patients with familial Mediterranean fever - a randomized controlled noninferiority trial. Arthritis Res Ther (2016) 18:85. doi:10.1186/ s13075-016-0980-7

80. Padeh S, Gerstein M, Berkun Y. Colchicine is a safe drug in children with familial Mediterranean fever. J Pediatr (2012) 161(6):1142-6. doi:10.1016/j. jpeds.2012.05.047

81. Jayaprakash V, Ansell G, Galler D. Colchicine overdose: the devil is in the detail. N Z Med J (2007) 120(1248):U2402.

82. Varughese GI, Varghese AI, Tahrani AA. Colchicine: time to rethink. $N Z$ Med J (2007) 120(1249):U2429.

83. Fradkin A, Yahav J, Zemer D, Jonas A. Colchicine-induced lactose malabsorption in patients with familial Mediterranean fever. Isr J Med Sci (1995) 31(10):616-20.

84. Mor A, Gal R, Livneh A. Abdominal and digestive system associations of familial Mediterranean fever. Am J Gastroenterol (2003) 98(12):2594-604. doi:10.1111/j.1572-0241.2003.08784.x

85. Batu ED, Arici ZS, Bilginer Y, Özen S. Current therapeutic options for managing familial Mediterranean fever. Expert Opin Orphan Drugs (2015) 3(9):1063-73. doi:10.1517/21678707.2015.1073149

86. Ben-Chetrit E, Navon P. Colchicine-induced leukopenia in a patient with familial Mediterranean fever: the cause and a possible approach. Clin Exp Rheumatol (2003) 21(4 Suppl 30):S38-40.

87. Choi SS, Chan KF, Ng HK, Mak WP. Colchicine-induced myopathy and neuropathy. Hong Kong Med J (1999) 5(2):204-7.

88. Malkinson FD, Lynfield YL. Colchicine alopecia. J Invest Dermatol (1959) 33:371-84. doi:10.1038/jid.1959.162

89. Yilmaz ROS, Ozyurt H, Erkorkmaz U. Serum vitamin B12 status in children with familial Mediterranean fever receiving colchicine treatment. Hong Kong J Paediatr (2011) 16:3-8.

90. Barsoum $\mathrm{H}$. The effect of colchicine on the spermatogenesis of rabbits. J Pharmacol Exp Ther (1955) 115(3):319-22. 
91. Merlin HE. Azoospermia caused by colchicine - a case report. Fertil Steril (1972) 23(3):180-1. doi:10.1016/S0015-0282(16)38823-9

92. American Academy of Pediatrics Committee on Drugs. Transfer of drugs and other chemicals into human milk. Pediatrics (2001) 108(3):776-89. doi:10.1542/peds.108.3.776

93. Ben-Chetrit E, Ben-Chetrit A, Berkun Y, Ben-Chetrit E. Pregnancy outcomes in women with familial Mediterranean fever receiving colchicine: is amniocentesis justified? Arthritis Care Res (2010) 62(2):143-8. doi:10.1002/ acr.20061

94. Diav-Citrin O, Shechtman S, Schwartz V, Avgil-Tsadok M, Finkel-Pekarsky $\mathrm{V}$, Wajnberg R, et al. Pregnancy outcome after in utero exposure to colchicine. Am J Obstet Gynecol (2010) 203(2):e1-6. doi:10.1016/j.ajog.2010.02.063

95. Finkelstein Y, Aks SE, Hutson JR, Juurlink DN, Nguyen P, Dubnov-Raz G, et al. Colchicine poisoning: the dark side of an ancient drug. Clin Toxicol (2010) 48(5):407-14. doi:10.3109/15563650.2010.495348

96. Zemer D, Pras M, Sohar E, Modan M, Cabili S, Gafni J. Colchicine in the prevention and treatment of the amyloidosis of familial Mediterranean fever. N Engl J Med (1986) 314(16):1001-5. doi:10.1056/NEJM198604173141601

97. Dinarello CA, Simon A, van der Meer JW. Treating inflammation by blocking interleukin-1 in a broad spectrum of diseases. Nat Rev Drug Discov (2012) 11(8):633-52. doi:10.1038/nrd3800

98. Ruperto N, Brunner HI, Quartier P, Constantin T, Wulffraat N, Horneff $\mathrm{G}$, et al. Two randomized trials of canakinumab in systemic juvenile idiopathic arthritis. N Engl J Med (2012) 367(25):2396-406. doi:10.1056/ NEJMoa1205099

99. van der Hilst J, Moutschen M, Messiaen PE, Lauwerys BR, Vanderschueren S. Efficacy of anti-IL-1 treatment in familial Mediterranean fever: a systematic review of the literature. Biologics (2016) 10:75-80. doi:10.2147/BTT.S102954

100. Brik R, Butbul-Aviel Y, Lubin S, Ben Dayan E, Rachmilewitz-Minei T, Tseng $\mathrm{L}$, et al. Canakinumab for the treatment of children with colchicine-resistant familial Mediterranean fever: a 6-month open-label, single-arm pilot study. Arthritis Rheumatol (2014) 66(11):3241-3. doi:10.1002/art.38777

101. Gul A, Ozdogan H, Erer B, Ugurlu S, Kasapcopur O, Davis N, et al. Efficacy and safety of canakinumab in adolescents and adults with colchicine-resistant familial Mediterranean fever. Arthritis Res Ther (2015) 17:243. doi:10.1186/ s13075-015-0765-4

102. Hashkes PJ, Spalding SJ, Giannini EH, Huang B, Johnson A, Park G, et al. Rilonacept for colchicine-resistant or -intolerant familial Mediterranean fever: a randomized trial. Ann Intern Med (2012) 157(8):533-41. doi:10.7326/0003-4819-157-8-201210160-00003

103. Alpay N, Sumnu A, Caliskan Y, Yazici H, Turkmen A, Gul A. Efficacy of anakinra treatment in a patient with colchicine-resistant familial Mediterranean fever. Rheumatol Int (2012) 32(10):3277-9. doi:10.1007/s00296-010-1474-6

104. Belkhir R, Moulonguet-Doleris L, Hachulla E, Prinseau J, Baglin A, Hanslik T. Treatment of familial Mediterranean fever with anakinra. Ann Intern Med (2007) 146(11):825-6. doi:10.7326/0003-4819-146-11-200706050-00023

105. Calligaris L, Marchetti F, Tommasini A, Ventura A. The efficacy of anakinra in an adolescent with colchicine-resistant familial Mediterranean fever. Eur J Pediatr (2008) 167(6):695-6. doi:10.1007/s00431-007-0547-3

106. Celebi ZK, Kucuksahin O, Sengul S, Tuzuner A, Keven K. Colchicine-resistant familial Mediterranean fever in a renal transplantation patient: successful treatment with anakinra. Clin Kidney J (2014) 7(2):219-20. doi:10.1093/ckj/stt164

107. Chae JJ, Wood G, Masters SL, Richard K, Park G, Smith BJ, et al. The B30.2 domain of pyrin, the familial Mediterranean fever protein, interacts directly with caspase-1 to modulate IL-1beta production. Proc Natl Acad Sci U S A (2006) 103(26):9982-7. doi:10.1073/pnas.0602081103

108. Estublier C, Stankovic Stojanovic K, Bergerot JF, Broussolle C, Seve P. Myositis in a patient with familial Mediterranean fever and spondyloarthritis successfully treated with anakinra. Joint Bone Spine (2013) 80(6):645-9. doi:10.1016/j.jbspin.2013.03.004

109. Gattringer R, Lagler H, Gattringer KB, Knapp S, Burgmann H, Winkler $\mathrm{S}$, et al. Anakinra in two adolescent female patients suffering from colchicine-resistant familial Mediterranean fever: effective but risky. Eur JClin Invest (2007) 37(11):912-4. doi:10.1111/j.1365-2362.2007.01868.x

110. Hennig S, Bayegan K, Uffmann M, Thalhammer F, Winkler S. Pneumonia in a patient with familial Mediterranean fever successfully treated with anakinra - case report and review. Rheumatol Int (2012) 32(6):1801-4. doi:10.1007/s00296-010-1429-y
111. Kuijk LM, Govers AM, Frenkel J, Hofhuis WJ. Effective treatment of a colchicine-resistant familial Mediterranean fever patient with anakinra. Ann Rheum Dis (2007) 66(11):1545-6. doi:10.1136/ard.2007.071498

112. Mercan R, Turan A, Bitik B, Tufan A, Haznedaroglu S, Goker B. Rapid resolution of protracted febrile myalgia syndrome with anakinra: report of two cases. Mod Rheumatol (2016) 26(3):458-9. doi:10.3109/14397595.2014.882221

113. Mitroulis I, Papadopoulos VP, Konstantinidis T, Ritis K. Anakinra suppresses familial Mediterranean fever crises in a colchicine-resistant patient. Neth J Med (2008) 66(11):489-91.

114. Moser C, Pohl G, Haslinger I, Knapp S, Rowczenio D, Russel T, et al. Successful treatment of familial Mediterranean fever with anakinra and outcome after renal transplantation. Nephrol Dial Transplant (2009) 24(2):676-8. doi:10.1093/ndt/gfn646

115. Ozen S, Bilginer Y, Aktay Ayaz N, Calguneri M. Anti-interleukin 1 treatment for patients with familial Mediterranean fever resistant to colchicine. J Rheumatol (2011) 38(3):516-8. doi:10.3899/jrheum.100718

116. Petropoulou AD, Robin M, Socie G, Galicier L. Transmission of familial Mediterranean fever mutation after bone marrow transplantation and successful treatment with anakinra. Transplantation (2010) 90(1):102-3. doi:10.1097/TP.0b013e3181d84cc3

117. Roldan R, Ruiz AM, Miranda MD, Collantes E. Anakinra: new therapeutic approach in children with familial Mediterranean fever resistant to colchicine. Joint Bone Spine (2008) 75(4):504-5. doi:10.1016/j. jbspin.2008.04.001

118. Sevillano AM, Hernandez E, Gonzalez E, Mateo I, Gutierrez E, Morales E, et al. Anakinra induces complete remission of nephrotic syndrome in a patient with familial mediterranean fever and amyloidosis. Nefrologia (2016) 36(1):63-6. doi:10.1016/j.nefro.2015.06.026

119. Soriano A, Verecchia E, Afeltra A, Landolfi R, Manna R. IL-1beta biological treatment of familial Mediterranean fever. Clin Rev Allergy Immunol (2013) 45(1):117-30. doi:10.1007/s12016-013-8358-y

120. Stankovic Stojanovic K, Delmas Y, Torres PU, Peltier J, Pelle G, Jeru I, et al. Dramatic beneficial effect of interleukin- 1 inhibitor treatment in patients with familial Mediterranean fever complicated with amyloidosis and renal failure. Nephrol Dial Transplant (2012) 27(5):1898-901. doi:10.1093/ndt/gfr528

121. Alpa M, Roccatello D. Canakinumab as rescue therapy in familial Mediterranean fever refractory to conventional treatment. Drug Des Devel Ther (2015) 9:1983-7. doi:10.2147/DDDT.S69117

122. Mitroulis I, Skendros P, Oikonomou A, Tzioufas AG, Ritis K. The efficacy of canakinumab in the treatment of a patient with familial Mediterranean fever and longstanding destructive arthritis. Ann Rheum Dis (2011) 70(7):1347-8. doi:10.1136/ard.2010.146878

123. Cetin P, Sari I, Sozeri B, Cam O, Birlik M, Akkoc N, et al. Efficacy of interleukin-1 targeting treatments in patients with familial Mediterranean fever. Inflammation (2015) 38(1):27-31. doi:10.1007/s10753-014-0004-1

124. Eroglu FK, Besbas N, Topaloglu R, Ozen S. Treatment of colchicine-resistant familial Mediterranean fever in children and adolescents. Rheumatol Int (2015) 35(10):1733-7. doi:10.1007/s00296-015-3293-2

125. Meinzer U, Quartier P, Alexandra JF, Hentgen V, Retornaz F, Kone-Paut I. Interleukin-1 targeting drugs in familial Mediterranean fever: a case series and a review of the literature. Semin Arthritis Rheum (2011) 41(2):265-71. doi:10.1016/j.semarthrit.2010.11.003

126. Ozcakar ZB, Ozdel S, Yilmaz S, Kurt-Sukur ED, Ekim M, Yalcinkaya F. Anti-IL-1 treatment in familial Mediterranean fever and related amyloidosis. Clin Rheumatol (2016) 35(2):441-6. doi:10.1007/s10067-014-2772-2

127. Topaloglu R, Batu ED, Orhan D, Ozen S, Besbas N. Anti-interleukin 1 treatment in secondary amyloidosis associated with autoinflammatory diseases. Pediatr Nephrol (2016) 31(4):633-40. doi:10.1007/s00467-015-3249-5

128. Bodar EJ, Kuijk LM, Drenth JP, van der Meer JW, Simon A, Frenkel J. On-demand anakinra treatment is effective in mevalonate kinase deficiency. Ann Rheum Dis (2011) 70(12):2155-8. doi:10.1136/ard.2011.149922

129. Bilgen SA, Kilic L, Akdogan A, Kiraz S, Kalyoncu U, Karadag O, et al. Effects of anti-tumor necrosis factor agents for familial Mediterranean fever patients with chronic arthritis and/or sacroiliitis who were resistant to colchicine treatment. J Clin Rheumatol (2011) 17(7):358-62. doi:10.1097/ RHU.0b013e31823682f5

130. Seyahi E, Ozdogan H, Celik S, Ugurlu S, Yazici H. Treatment options in colchicine resistant familial Mediterranean fever patients: 
thalidomide and etanercept as adjunctive agents. Clin Exp Rheumatol (2006) 24(5 Suppl 42):S99-103.

131. Kaplan E, Mukamel M, Barash J, Brik R, Padeh S, Berkun Y, et al. Protracted febrile myalgia in children and young adults with familial Mediterranean fever: analysis of 15 patients and suggested criteria for working diagnosis. Clin Exp Rheumatol (2007) 25(4 Suppl 45):S114-7.

132. Sidi G, Shinar Y, Livneh A, Langevitz P, Pras M, Pras E. Protracted febrile myalgia of familial Mediterranean fever. Mutation analysis and clinical correlations. Scand J Rheumatol (2000) 29(3):174-6. doi:10.1080/030097400750002058

133. Langevitz P, Zemer D, Livneh A, Shemer J, Pras M. Protracted febrile myalgia in patients with familial Mediterranean fever. J Rheumatol (1994) 21(9):1708-9.

134. Majeed HA, Al-Qudah AK, Qubain H, Shahin HM. The clinical patterns of myalgia in children with familial Mediterranean fever. Semin Arthritis Rheum (2000) 30(2):138-43. doi:10.1053/sarh.2000.16646

135. Ozen S. Changing concepts in familial Mediterranean fever: is it possible to have an autosomal-recessive disease with only one mutation? Arthritis Rheum (2009) 60(6):1575-7. doi:10.1002/art.24565

136. Ben-Zvi I, Krichely-Vachdi T, Feld O, Lidar M, Kivity S, Livneh A. Colchicine-free remission in familial Mediterranean fever: featuring a unique subset of the disease-a case control study. Orphanet J Rare Dis (2014) 9:3. doi:10.1186/1750-1172-9-3
137. Ozen S, Demirkaya E, Duzova A, Erdogan O, Erken E, Gul A, et al. FMF50: a score for assessing outcome in familial Mediterranean fever. Ann Rheum Dis (2014) 73(5):897-901. doi:10.1136/annrheumdis-2013-204719

138. Piram M, Kone-Paut I, Lachmann HJ, Frenkel J, Ozen S, KuemmerleDeschner J, et al. Validation of the auto-inflammatory diseases activity index (AIDAI) for hereditary recurrent fever syndromes. Ann Rheum Dis (2014) 73(12):2168-73. doi:10.1136/annrheumdis-2013-203666

139. Ter Haar NM, Annink KV, Al-Mayouf SM, Amaryan G, Anton J, Barron KS, et al. Development of the autoinflammatory disease damage index (ADDI). Ann Rheum Dis (2016). doi:10.1136/annrheumdis-2016-210092

Conflict of Interest Statement: SÖ has received consultancy and speaker fees from Novartis and Sobi and R-Pharma in the past. The remaining authors declare no conflict of interest.

Copyright $\odot 2017$ Özen, Batu and Demir. This is an open-access article distributed under the terms of the Creative Commons Attribution License (CC BY). The use, distribution or reproduction in other forums is permitted, provided the original author(s) or licensor are credited and that the original publication in this journal is cited, in accordance with accepted academic practice. No use, distribution or reproduction is permitted which does not comply with these terms. 